\title{
KOTONA VILJELLYN KEVÄTVILJAN SIEMENKELPOISUUDESTA
}

\author{
Aarne Hilli \\ Valtion siementarkastuslaitos, Helsinki
}

Saapunut 21. 10. 1959

Tutkimuksen tarkoituksena oli selvittää millaisella kylvösiemenellä kevätviljojen kylvöt keväällä 1959 suoritettiin. Edellisen vuoden sato, etenkin kaura ja kevätvehnä, oli verraten yleisesti hallan vikuuttamaa.

Tutkittavien siemennäytteiden keräämisen ja lähettämisen hoitivat siemenkonsulentit. Näytteet otettiin kylvöaikana siten valituilta tiloilta, että ne edustaisivat kotona viljellyn siementavaran keskitasoa eri puolilta maata (kartta 1).

Tutkittavia siemennäytteitä (n.s. vakkanäytteitä) saapui yhteensä 855 . Ne jakautuivat viljelijöiltä saatujen tietojen perusteella taulukon 1 mukaisesti.

\section{Tutkimuksen tulokset}

Tutkimusnäytteistä suoritettiin valtion siementarkastuslaitoksessa puhtausja itävyysmääritykset. Samalla tehtiin silmävarainen tarkastus siemenen aitoudesta ja terveydestä.

Puhtaus- ja aitoustarkastuksista saadut keskimääräiset tulokset on esitetty taulukossa 2.

Vaarallisina rikkaruohoina esiintyi kaikissa tutkituissa viljoissa hukkakaura, peltoretikka, hiirenruis sekä ruiskaunokki. Muita rikkaruohonsiemeniä oli kaurassa 19 lajia (yleisimpiä pillike, pihatatar, peltovirvilä, ukontatar ja peltohatikka), kevätvehnässä 15 lajia (yleisimpiä kiertotatar, pillike ja peltovirvilä) ja ohrassa 12 lajia (yleisimpiä kiertotatar, pillike, ukontatar, jauhosavikka sekä peltomatara).

Toisten hyötykasvien siemenistä olivat yleisimpiä kauran joukossa ohra, vehnä ja ruis, kevätvehnässä ohra, kaura ja ruis sekä ohrassa kaura, ruis, vehnä ja rölli. 


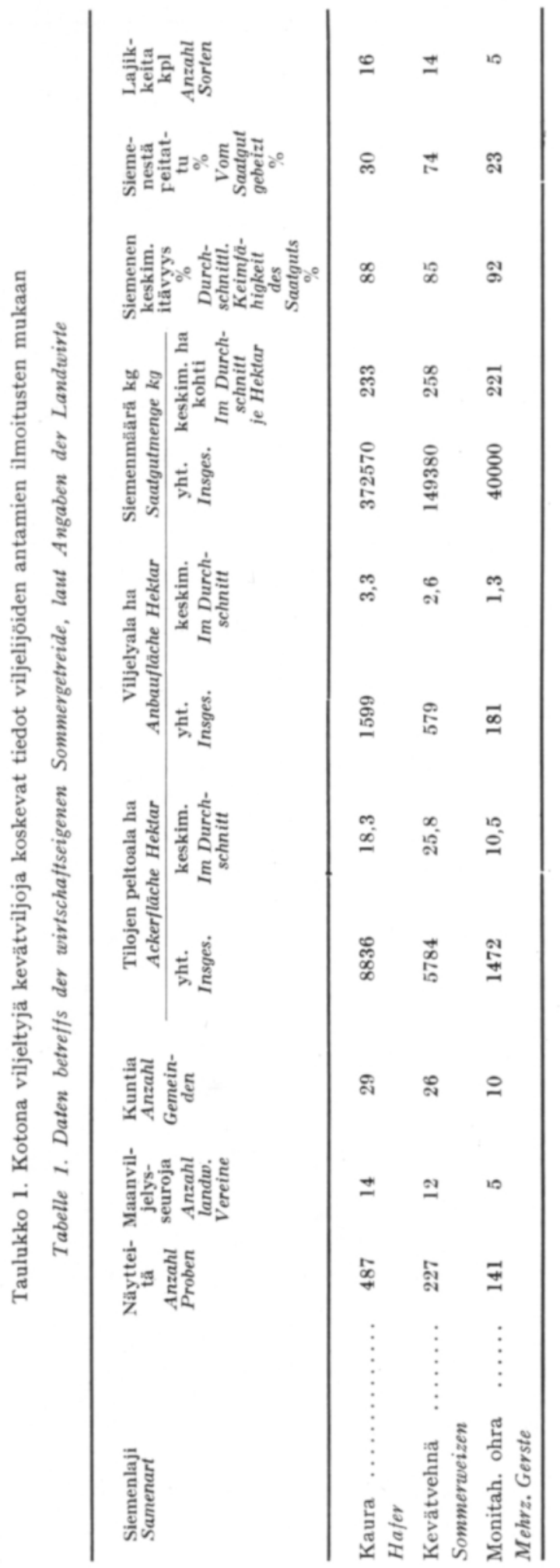




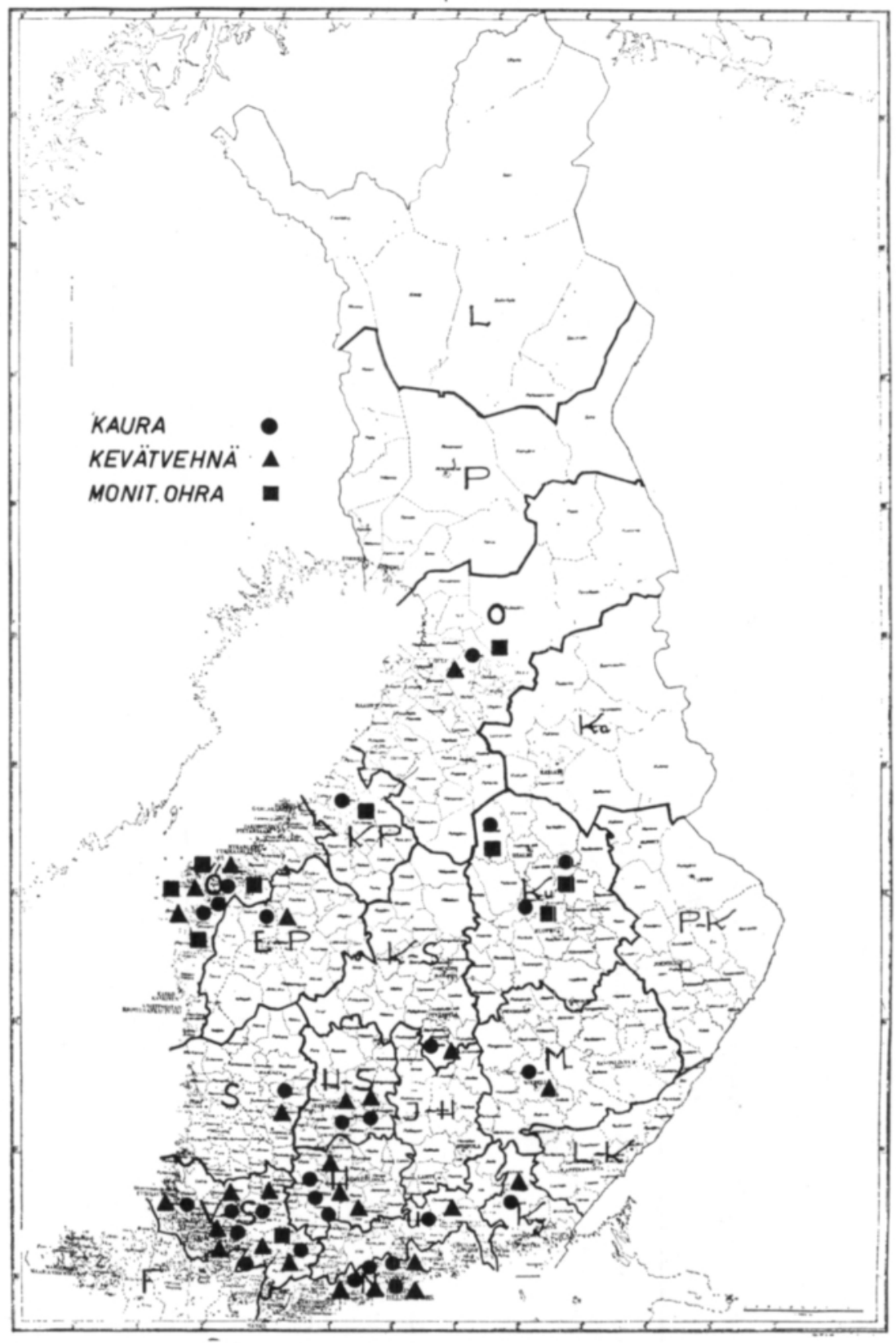

Kartta 1. Tutkittujen kaura-, kevätvehnä- ja ohranäytteiden alkuperäkunnat eri maanviljelysseurojen alueilla.

Karte 1. Die Gemeinden wovon die untersuchten Proben von Hafer, Sommerweizen und Gerste von Bezirken der landwirtschaftlichen Vereine gesammelt sind. 


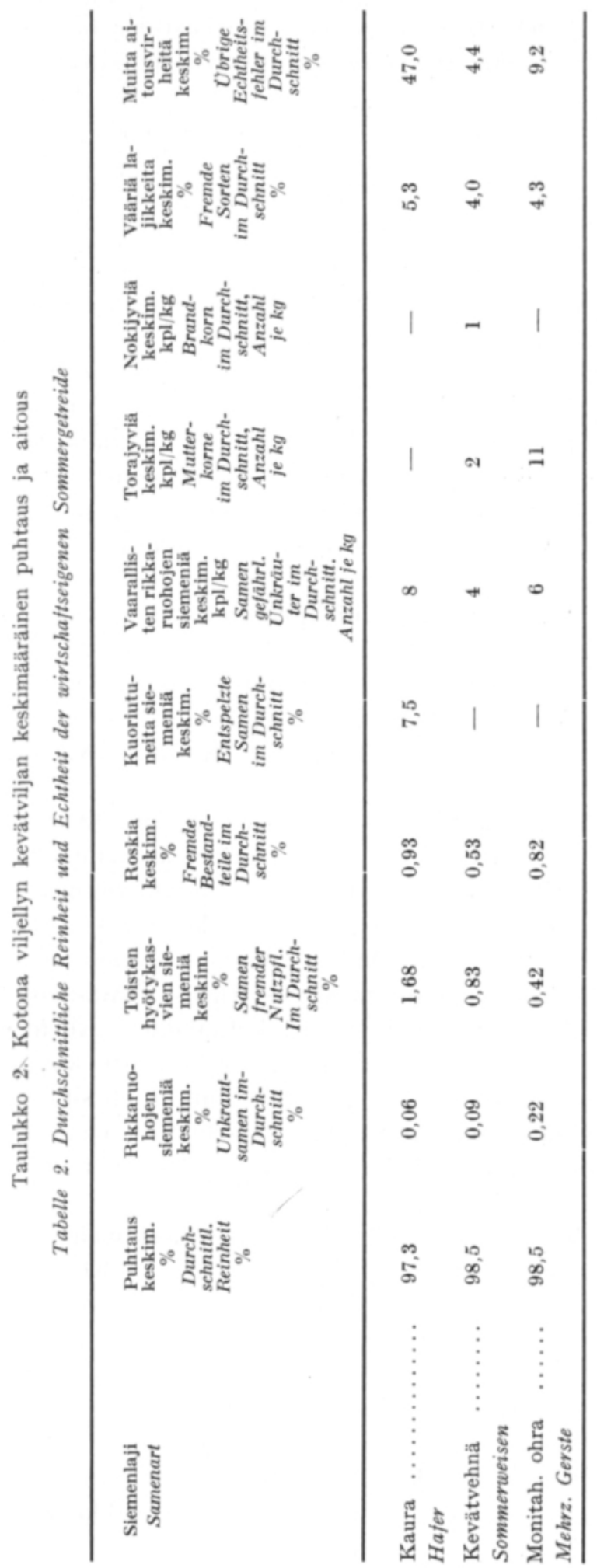


Tutkittujen viljojen itävyys- ja terveystarkastuksista saadut keskimääräiset tulokset on esitetty taulukossa 3 sekä itävyyden jakautuminen itävyysluokkiin taulukossa 4.

\section{Tulosten tarkastelua}

Suoritettu tutkimus osoittaa, että huomattavan suuret kaura-, kevätvehnäja ohra-alat on keväällä 1959 kylvetty siemenellä, jossa on ollut monenlaisia virheitä.

Käytetyt siemenmäärät hehtaaria kohti ovat olleet normaaliset, mutta perustuneet liian korkeisiin itävyysarvoihin. Erot viljelijäin ja siementarkastuslaitoksen saamien itävyyslukujen välillä ovat keskimäärin kauralla $9 \%$, ohralla $7 \%$ ja kevätvehnällä $6 \%$. Kotioloissa suoritettu itävyystarkastus on antanut liian korkeita arvoja ilmeisesti senvuoksi, että hallan, homeiden, piunnin, kuivauksen ym. syiden vuoksi vaillinaisesti itäneet siemenet on laskettu moitteettomasti itäviksi, jota ne kuitenkaan eivät ole.

Kylvösiemenestä on peitattu viljelijöiden antaman tiedon mukaan kevätvehnästä $74 \%$, kaurasta $30 \%$ ja ohrasta $23 \%$.

Eri lajikkeita on viljelijöiden ilmoituksen mukaan ollut kaurasta 16 (yleisimpinä Tammi, Sisu, Eho, Orion III, Sol II ja Pendek), kevätvehnästä 14 (yleisimpinä Apu, Timantti II, Svenno, Timantti I, Kärni ja Norröna) sekä ohrasta 5 (yleisimpinä Tammi ja Pirkka).

Aitoustutkimus osoitti, että annetut lajiketiedot olivat osittain virheellisiä. Heikoin aitous on ollut kauralla. Täysin väärällä lajikenimellä saapuneita kauranäytteitä oli $5.3 \%$ ja muita aitousvirheitä (sekalajikkeisuus, väri- ja muotoviat) oli $47 \%$. Ohranäytteistä oli täysin vääriä lajikkeita $4.3 \%$ sekä muita aitousvirheitä sisältäneitä $9.2 \%$. Kevätvehnä oli lajikepuhtainta. Väärällä lajikenimellä tulleita näytteitä oli $4.0 \%$ ja muita aitousvirheitä sisältäneitä $4.4 \%$.

Vakkanäytteiden puhtaus oli yleensä kohtalainen. Kevätvehnällä ja ohralla puhtaus täytti puhtaisiin siemeniin nähden keskimäärin kauppasiemenen 19581959 alimman vaatimuksen $(98.5 \%)$, mutta kauralla oli sitä alhaisempi $(97.3 \%)$.

Rikkaruohoisuuden suhteen oli kaura $(0.06 \%)$ sekä kevätvehnä $(0.09 \%)$ kauppasiemenvaatimukset (korkeintaan $0.1 \%$ ) täyttävää, mutta ohra sensijaan sitä rikkaruohoisempaa $(0.22 \%)$.

Toisten hyötykasvien siemeniä oli kaurassa keskimäärin $1.68 \%$, joten se ei täyttänyt kauppasiemenvaatimusta (enintään $1.0 \%$ ). Kevätvehnässä oli toisten hyötykasvien siemeniä $0.83 \%$ eikä sekään täyttänyt kauppasiemenvaatimusta (enintään $0.5 \%$ ). Ohra sensijaan täytti tässä suhteessa tarkastusvuoden 19581959 vaatimukset. Toisten hyötykasvinsiemenien määrä ohranäytteissä oli keskimäärin $0.42 \%$ ja vaatimus oli korkeintaan $0.5 \%$.

Vakkanäytteiden roskaisuus oli kaikilla tutkituilla viljoilla runsasta. Roskaisinta oli kaura $(0.93 \%)$, senjälkeen ohra $(0.82 \%)$ ja kevätvehnä $(0.53 \%)$.

Kuoriutuneiden siemenien määrä kauralla oli vakkanäytteissä keskimäärin $7.5 \%$, joka on yleistä keskitasoa korkeampi. 


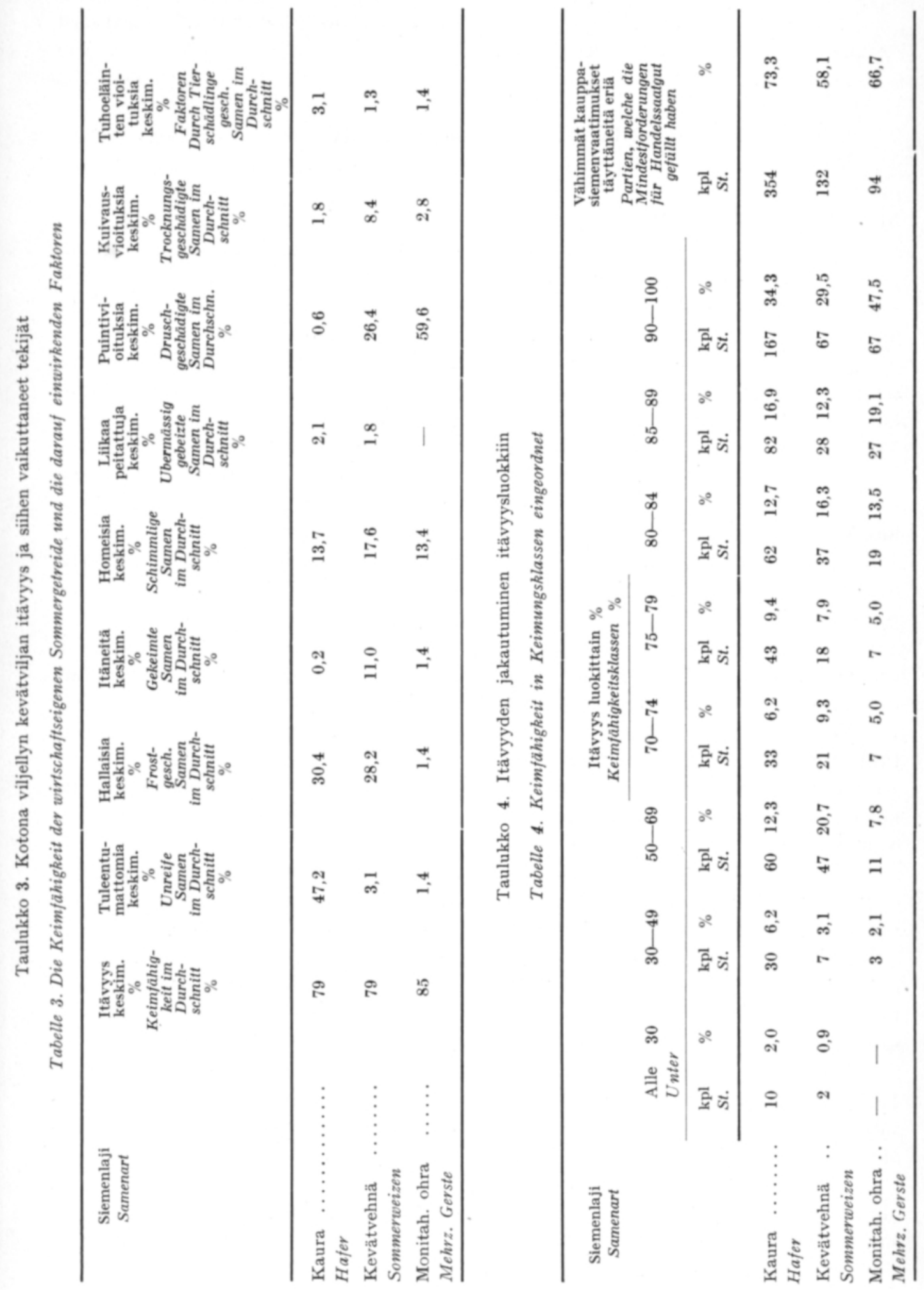


Vaarallisten rikkaruohonsiemenien määrä oli vakkanäytteissä kauralla 8, ohralla 6 ja kevätvehnällä 4 kappaletta kilossa.

Torajyviä esiintyi runsaimmin ohrassa $(11 \mathrm{kpl} / \mathrm{kg})$, vähemmän kevätvehnässä (2 kpl/kg) eikä kaurassa laisinkaan.

Kokonaisia nokijyviä tavattiin ainoastaan kevätvehnässä $1 \mathrm{kpl} / \mathrm{kg}$.

Kauppasiemenen vähimmät puhtausvaatimukset kaikissa suhteissa täyttäneitä eriä oli kaurasta $52.2 \%$, kevätvehnästä $48.5 \%$ ja monitahoisesta ohrasta $51.1 \%$.

Vakkanäytteiden keskimääräinen itävyys oli odotettua korkeampi (kauralla ja kevätvehnällä $79 \%$, ohralla $85 \%$ ). Itävyysluokittain tarkasteltuna oli kuitenkin todettavissa varsin suuria vaihteluja etenkin kauralla ja kevätvehnällä, jotka olivat enimmän kärsineet halloista.

Tarkastusvuotena 1958-1959 oli kauppasiemenen alimpana itävyysvaatimuksena kotimaisella kauralla $75 \%$, kevätvehnällä $80 \%$ ja monitahoisella ohralla $85 \%$. Tämän vaatimuksen täyttäneitä siemeneriä tutkitusta sadosta oli kauralla $73.3 \%$, kevätvehnällä $58.1 \%$ ja monitahoisella ohralla $66.7 \%$.

Vakkanäytteiden keskimääräinen itävyys oli tarkastusvuotena 1958-1959 tutkittuun kauppasiemeneen verrattuna, ohraa lukuunottamatta, lähimain samaa luokkaa. Kauran kauppasiemenen (9953 näytettä) keski-itävyys oli nimittäin $78.9 \%$ (vakkanäytteillä $79 \%$ ), kevätvehnän kauppasiemenen (5535 näytettä) $81.6 \%$ (vakkanäytteillä $79 \%$ ) ja monitahoisen ohran kauppasiemenen (5333 näytettä) $90 \%$ (vakkanäytteillä $85 \%$ ).

Itävyyttä alentavina virheinä todettiin vakkasiemennäytteissä tuleentumattomuutta, hallavioittumia, itäneisyyttä, homeisuutta sekä peittauksen, puinnin, kuivauksen ja tuhoeläinten aiheuttamia vioituksia.

Tuleentumattomuus oli yleisintä kaurassa $(47.2 \%)$. Toisissa viljoissa oli tuleentumattomia, vihreitä jyviä vain vähän (kevätvehnässä $3.1 \%$, ohrassa $1.4 \%$ ), Kauran tuleentumattomuus johtunee paitsi sääsuhteista, liian myöhäisten lajikkeiden viljelystä, myöhäisestä kylvöajasta, epäedullisesta kasvupaikasta, jälkiversonnasta ym. seikoista.

Hallan vioitukset olivat yleisimpiä kaurassa (30.4\%) ja kevätvehnässä $(28.2 \%)$, ohrassa niitä sensijaan oli vain vähän $(1.4 \%)$. Hallavauriot olivatkin ilmeisesti yhtenä pääsyynä kauran ja kevätvehnän heikentyneeseen itävyyteen.

Itäneisyyttä ilmeni suhteellisen vähän kaurassa $(0.2 \%)$ ja ohrassa $(1.4 \%)$, mutta sensijaan enemmän kevätvehnässä $(11.0 \%$ ). Aikaisemmin valtion siementarkastuslaitoksessa suoritetun erikoistutkimuksen mukaan lievä tähkäidäntä ei sanottavasti alenna kylvösiemenen lopullista itävyyttä.

Homeisuus oli lähimain yhtä runsasta kaikilla tutkituilla viljoilla (ohralla $13.4 \%$, kauralla $13.7 \%$ ja kevätvehnällä $17.6 \%$ ) ja aiheutti se huomattavaa itävyyden alentumista. Homeisuus johtui ilmeisesti epäedullisista kasvu- ja korjuuolosuhteista sekä puutteellisesta kuivauksesta ja säilytyksestä.

Liikaa peitattuja siemeneriä oli kauralla $2.1 \%$, kevätvehnällä $1.8 \%$ eikä ohralla ensinkään. Ilmiö, joka johtaa itävyyden alentumiseen, johtuu käyttöohjeita suuremman peittausainemäärän käytöstä sekä puutteellisista peittauslaitteista. Puintivioituksia oli runsaimmin ohrassa $(59.6 \%$ ) ja kevätvehnässä $(26.4 \%)$, 
kaurassa niitä oli vain vähän $(0.6 \%)$. Puintivioitus aiheutuu liian ankarasta puinnista ja johtaa, jos alkio on vahingoittunut, itävyyden alentumiseen. Ohraa puitaessa vihneenkatkoja myös rikkoo usein jyviä.

Kuivausvioituksia oli tutkitussa siementavarassa suhteellisen vähän (kevätvehnässä $8.4 \%$, ohrassa $2.8 \%$ ja kaurassa $1.8 \%$ ) aiheutuen ilmeisesti edellisen syksyn kohtalaisen edullisista korjuuolosuhteista. Kuivausvioitukset johtuvat liian korkean kuivauslämmön käyttämisestä sekä liian lyhyestä kuivausajasta ja johtavat ne aina itävyyden alentumiseen.

Tuhoeläinten aiheuttamat vioitukset tutkitussa kylvösiemenessä olivat pääasiassa hiirien ja rottien aikaansaamia talvivarastoinnin aikana. Enimmän oli tuhoeläinvioituksia kaurassa $(3.1 \%)$, vähemmän ohrassa $(1.4 \%)$ ja kevätvehnässä $(1.3 \%)$. Tuhoeläinten aiheuttamat vioitukset alentavat itävyyttä, jos siemenen alkio-osa on syöty tai vaurioitunut.

\section{$P \ddot{a} a ̈ t e l m i \ddot{a}$}

Suoritettu vakkatutkimus vuoden 1959 kevätviljan siemenestä toi esille muun muassa seuraavia seikkoja.

Käytetyt siemenmäärät olivat normaalisen suuruisia, mutta perustuivat todellista korkeampiin itävyyslukuihin. Kotioloissa olisi käytettävä siemenkelpoisuuden selvittämisessä orastumismääritystä, jolloin virhemahdollisuudet ovat pienemmät kuin itävyysmäärityksessä.

Aitousvirheet (väärä lajike, sekalajikkeisuus, väri- ja muotoviat) olivat yleisimpiä kauralla, senjälkeen ohralla ja kevätvehnällä.

Puhtausvirheistä olivat yleisimpiä runsas toisten hyötykasvien siemenien sekä roskien määrä. Tutkituista viljoista oli kauran puhtaus selvästi huonompi kevätvehnän ja ohran puhtautta.

Itävyysvirheistä olivat tärkeimpiä hallavioittumat (etenkin kauralla ja ohralla), tuleentumattomuus (etenkin kauralla), itäneisyys (etenkin kevätvehnällä), homeisuus (kaikilla viljoilla), puintivioitukset (etenkin ohralla ja kevätvehnällä) sekä kuivausvioitukset (etenkin kevätvehnällä).

Itävyyttä alensivat ilmeisesti eniten siemenissä todetut hallan vauriot, homeisuus sekä puinti- ja kuivausvioitukset.

Tutkitusta sadosta täytti tarkastusvuoden kauppasiemenvaatimukset puhtauden suhteen noin puolet, itävyyden puolesta noin kaksi kolmannesta.

Havainnot tutkitulla siemenellä kylvettyjen peltojen orastumisesta sekä arviot saaduista satotuloksista osoittivat myös puolestaan, että käytetyn kotoisen kylvösiemenen laatu oli ollut monessa suhteessa puutteellista. 
UBBR DIE SAATTAUGLICHKEIT VON WIRTSCHAFTSEIGENEM SOMMERGETREIDE

\author{
AARNe Hilli
}

\title{
Staatliche Samenkontrollanstalt, Helsinki
}

Eine Untersuchung betreffs der Tauglichkeit von wirtschaftseigenem Sommergetreide als Saatgut ist an 855 Proben ausgeführt worden, davon 487 Proben von Hafer, 227 von Sommerweizen und 141 von mehrzeiliger Gerste. Die Proben wurden von verschiedenen Landgütern gesammelt, deren Wahl so getroffen wurde, dass das mittlere Niveau des Saatguts aus den verschiedenen Teilen von Finnland möglichts gut vertreten ist. Die Proben wurden auf ihre Echtheit, Reinheit, Keimfähigkeit und Gesundheit untersucht.

An Echtheitsfehlern kamen vor: falsche Sortenbezeichnung, Sortenmischung sowie Farb- und Formfehler. Die schlechtesten Echtheitsergebnisse zeitigte der Hafer, der auch die grösste Sortenzahl aufwies. Sommerweizen und Gerste waren am sortenreinsten.

Festgestellte Reinheitsfehler waren: Samen von Unkraut und von fremden Nutzpflanzen, fremde Bestandteile sowie beim Hafer Entspelzung. Die Unkrautbeimengung war bei Gerste am höchsten. Als gefährliche Unkrautarten wurde in sämtlichen Getreiden Flughafer (Avena fatua), Hederich (Raphanus raphanistrum), Roggentrespe (Bromus secalinus) sowie Kornblume (Centaurea cyanus) festgestellt. Die Menge artfremder Nutzpflanzen war im Hafer am höchsten. Fremde Beimengungen wurden am meisten in Hafer und Gerste gefunden. Von den Hafersamen waren im Durchschnitt $7.5 \%$ entspelzt.

Folgende Fehler bezüglich der Keimfähigkeit kamen in den untersuchten Proben vor: Unreifheit (vor allem im Hafer), Frostschädigung (insbesondere in Hafer und Sommerweizen), gekeimte Samen (insbesondere im Sommerweizen), Schimmelbefall (in allen Getreiden), Beizschädigung (vor allem imSommerweizen), Druschverletzung (insbesondere in Gerste und Sommerweizen), Trocknungsschäden (vor allem im Sommerweizen) sowie Schädigung durch Tierschädlinge (vor allem in Gerste).

Als wichtigste, die Keimfähigkeit herabsetzende Faktoren waren unter den erwähnten Keimfähigkeitsfehlern offenbar Frostschädigung, Schimmelbefall sowie Drusch- und Trocknungsschäden anzusprechen.

An Gesundheitsfehlern wurden ausser den vorerwähnten Schädigungen durch Schimmelpilze (Fusarium) u.dgl. auch Mutterkorn (Claviceps purpurea) in Gerste und Sommerweizen sowie Brandkorn (Tilletia caries) im Sommerweizen beobachtet. 